\title{
The Potential of Non-Ionic Surfactant Against P-Glycoprotein Efflux Transporters for Drug Development System
}

\author{
Kulsirirat $\mathrm{T}^{1}$, Rukthong $\mathrm{P}^{2}$, Dechwongya $\mathrm{P}^{1}$ and Sathirakul $\mathrm{K}^{1,3^{*}}$ \\ ${ }^{1}$ Faculty of Pharmacy, Mahidol University, Bangkok, Thailand \\ ${ }^{2}$ Faculty of Pharmacy, Srinakharinwirot University, Nakhon-Nayok, Thailand \\ ${ }^{3}$ Drug Discovery and Development Center, Thammasart University (Rangsit campus), Pathum Thani, Thailand
}

\begin{abstract}
Polysorbates (Tweens) are widely used in pharmaceutical formulations as excipients, such as stabilizer or solubilizer, for poorly soluble drugs. The efflux transporters ABCB1 (P-glycoprotein, P-gp) play an essential role in limiting the oral bioavailability of drugs. P-gp is expressed in the intestinal epithelium, thereby, it significantly impairs the systemic absorption of various active substances. The present study is to investigate a new property of polysorbates including its ability to stimulate or inhibit the efflux transporter P-glycoprotein (P-gp) using Pgp-Glo ${ }^{\mathrm{TM}}$ assay systems. The Pgp-Glo ${ }^{T M}$ assay systems are luminescent P-glycoprotein (P-gp) ATPase assays. It detected the effect of substance on recombinant human P-gp in a cell membrane fraction. The investigation showed that the concentration of $0.1 \%$ Tween 80 is an inhibitor of P-gp ATPase activity, whereas, the concentrations of $0.5 \%$ and $1 \%$ of Tween 80 demonstrated as a stimulator. All of these concentrations of Tween 20 were observed to be an inhibitory effect on P-gp ATPase activity.
\end{abstract}

Keywords: P-glycoprotein (P-gp); Non-ionic surfactant; HighThroughput screening; Bioluminescence; Pgp-Glo ${ }^{\text {тs }}$ assay; Efflux transporters

\section{Introduction}

The number of poorly soluble and lipophilic drugs with limited oral bioavailability among the new drug entities entering formulation development has increased over the last years. In many cases lower oral bioavailability entails higher inter-individual variability in bioavailability [1]. This can result in an inadequate control of plasma concentrations and pharmacological effects. Besides solubility and gastric stability, metabolic processes as well as transporter-mediated efflux play an essential role in influencing oral bioavailability of drugs [2]. P-glycoprotein (P-gp), also known as MDR1 and ABCB1, is a $170 \mathrm{kDa}$ integral plasma membrane protein that functions as an ATP-dependent drug efflux pump and plays an essential role in multi-drug resistance and certain adverse drug-drug interactions [3]. Its efflux mechanism involves the protein binding to the ATP and requires energy derived by the hydrolysis of ATP to ADP in the presence of adenosine-triphosphatase enzyme (ATPase) [4]. P-gp belongs to the ATP-binding cassette $(\mathrm{ABC})$ transporter subfamily that combines a wide range of proteins found in a number of different species. $\mathrm{ABC}$ transport proteins mediate the transport of a diversity of structurally different substances like amino acids, ions, peptides and also a variety of drugs through cell membranes [4]. A common method to improve the oral bioavailability of drugs is the use of solubilizing agents like complex forming hydroxypropyl $\beta$ cyclodextrin, co-solvents or surfactants in drug formulations. However, the knowledge about interactions between nonionic surfactants and the efflux transporter P-gp is limited up to date. In this study, to investigated whether nonionic surfactant stimulated or inhibited the ATPase activity of P-gp using Pgp-Glo ${ }^{\mathrm{TM}}$ assay systems.

\section{Methods}

\section{Preparation of buffers and solutions}

The Pgp-Glo ${ }^{\text {ma }}$ assay systems contain the necessary reagents for performing luminescent P-glycoprotein (P-gp) ATPase assays. The ATP detection buffer was thawed and equilibrated to room temperature. Then the ATP detection buffer was shaken briefly to resuspend any precipitate that may form after freezing. Then the entire content of the bottle of ATP detection buffer was transferred to the amber bottle containing the lyophilized ATP detection substrate and swirled or inverted several times to obtain a homogeneous solution of ATP detection reagent. Finally, 2.5 fold of concentration of test compounds in Pgp-Glo ${ }^{\mathrm{m}}$ assay buffer were prepared.

\section{Preperation of P-gp membranes}

The Pgp-Glo ${ }^{\text {mo }}$ assay system detects the effects of compounds on recombinant human P-gp in a cell membrane fraction. The P-gp membranes were prepared rapidly at $37^{\circ} \mathrm{C}$ and were immediately kept on ice until they became ready to use. Unused P-gp membranes were dispensed into single-use aliquots and stored at $-70^{\circ} \mathrm{C}$. Then $5 \mathrm{mg} / \mathrm{ml}$ membranes were diluted to $1.25 \mathrm{mg} / \mathrm{ml}$ with Pgp-Glo ${ }^{\text {ma }}$ assay buffer.

\section{Performing the assay}

The Pgp-Glo ${ }^{\mathrm{rm}}$ assay systems were used to analyze the effects of polysorbates (Tweens) on the activity of P-gp. Preperations of P-gp reaction mixtures and ATP reagent were done as described above. 20 $\mu \mathrm{l}$ of polysorbates were prepared in different concentrations $(0.1,0.5$ and $1 \% \mathrm{v} / \mathrm{v}$ ), Verapamil (positive control as P-gp substrate, $0.5 \mathrm{mM}$ ) and sodium orthovanadate (P-gp inhibitor, $0.25 \mathrm{mM}$ ) were added into a white opaque 96 -well plate. P-gp was then added into the well containing the test substances and then this well were incubated at $37^{\circ} \mathrm{C}$ for $40 \mathrm{~min}$. The reactions were stopped and luminescence was initiated by adding

*Corresponding author: Sathirakul K, Drug Discovery and Development center, Thammasart University (Rangsit campus), Pathum Thani, Thailand, Tel: +66863208895; E-mail: pyksk2001@yahoo.com.sg

Received May 17, 2017; Accepted September 27, 2017; Published October 05, 2017

Citation: Kulsirirat T, Rukthong P, Dechwongya P, Sathirakul K (2017) The Potential of Non-Ionic Surfactant Against P-Glycoprotein Efflux Transporters for Drug Development System. J Bioequiv Availab 9: 528-529. doi: 10.4172/jbb.1000357

Copyright: (C) 2017 Kulsirirat T, et al. This is an open-access article distributed under the terms of the Creative Commons Attribution License, which permits unrestricted use, distribution, and reproduction in any medium, provided the original author and source are credited. 
Citation: Kulsirirat T, Rukthong P, Dechwongya P, Sathirakul K (2017) The Potential of Non-lonic Surfactant Against P-Glycoprotein Efflux Transporters for Drug Development System. J Bioequiv Availab 9: 528-529. doi: 10.4172/jbb.1000357

ATP detection reagent to the well. The luminescence of all samples was measured by a GloMax Explorer reader.

\section{Analysis of results}

ATP concentrations has an effect on the generation of luminescence from the Pgp-Glo ${ }^{\text {max }}$ assay system. Reactions in which no ATP was consumed generate the brightest signals (Figure 1). Reactions where ATP was consumed have relatively lower luminescent signals, reflecting lower ATP concentrations. For example, a sample with $1.25 \mathrm{mM}$ ATP emitted half of the light produced by a sample with $2.5 \mathrm{mM}$ ATP during the reaction. Within a given experiment, differences luminescence in the samples were used to calculate the basal P-gp ATPase activity from $\mathrm{Na}_{3} \mathrm{VO}_{4}$-treated samples $\left(\mathrm{RLU}_{\mathrm{Na} 3 \mathrm{VO} 4}\right)$ and untreated $(\mathrm{NT})$ samples $\left(\mathrm{RLU}_{\mathrm{NT}}\right)$ to determine $\Delta \mathrm{RLU}_{\text {basal }}\left(\mathrm{RLU}_{\mathrm{Na} 3 \mathrm{VO} 4}-\mathrm{RLU}_{\mathrm{NT}}=\Delta \mathrm{RLU}_{\text {basal }}\right)$ and the effect of a test compound on P-gp ATPase activity from $\mathrm{Na}_{3} \mathrm{VO}_{4}$-treated samples $\left(\mathrm{RLU}_{\mathrm{Na3VO}}\right)$ and test compound-treated samples $\left(\mathrm{RLU}_{\mathrm{TC}}\right)$ to determine $\Delta \mathrm{RLU}_{\mathrm{TC}}\left(\mathrm{RLU}_{\mathrm{Na} 3 \mathrm{VO} 4}-\mathrm{RLU}_{\mathrm{TC}}=\Delta \mathrm{RLU}_{\mathrm{TC}}\right)$. If test compounds are more than the basal P-gp ATPase activity, then the test compounds are stimulators of P-gp ATPase activity. If test compounds are equal in activity with the basal P-gp ATPase activity, then the test compound has no effect on P-gp ATPase activity. If test compounds less than basal P-gp ATPase activity, then the test compounds are inhibitors of P-gp ATPase activity. The Pgp-Glo ${ }^{\text {ma }}$ assay systems rely on the ATP-dependence of the light-generating reaction of firefly luciferase. After a pool of ATP had been first exposed to the P-gp ATPase, ATP consumption was detected as a decrease in luminescence from a second reaction with a recombinant firefly luciferase (Ultra-Glo ${ }^{\text {Tit }}$ Luciferase).

\section{Results and Discussion}

The influence of Tween 20 and Tween 80 on the activity of P-gp, which is the key enzyme to determine the bioavailability of drug administrated, was investigated by in vitro P-gp activity assay. In this experiment, Tween 20 and Tween 80 were incubated independently on the P-gp membranes. It was observed that the luminescence signals generated by the test compounds significantly changed when compared to those of the basal P-gp ATPase activity. However, the Tween 80 showed a decrease in P-gp ATPase activity when compared to the basal P-gp ATPase activity at the concentration of $0.1 \% \mathrm{v} / \mathrm{v}$ whereas the Tween 80 represented an increase in concentrations of 0.5 and $1 \% \mathrm{v} / \mathrm{v}$ in P-gp ATPase activity (Figure 2). As shown in (Figure 3), tween 20 showed a decrease in P-gp ATPase activity when compared to the basal P-gp ATPase activity at all different concentrations in the experiment. The development of further specific P-gp targeting inhibitors is foreseen in the nearest future to tackle and overcome the P-gp induced MDR and bioavailability problems.

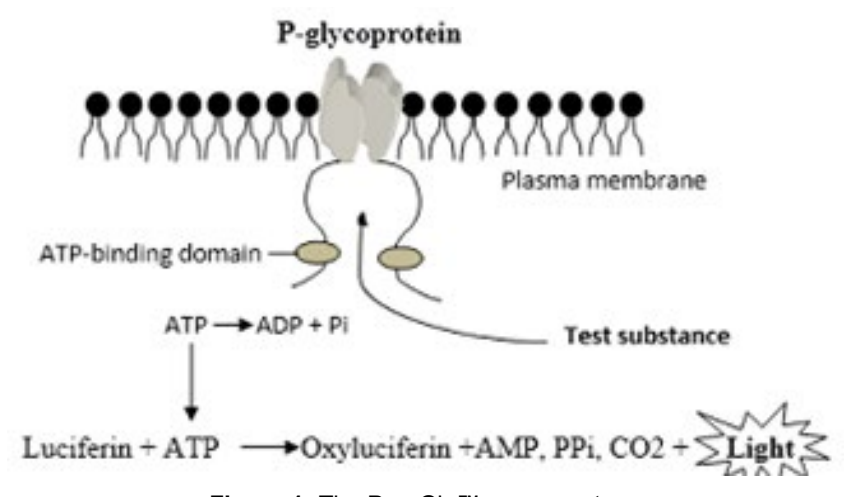

Figure 1: The Pgp-Glo ${ }^{\mathrm{TM}}$ assay system.

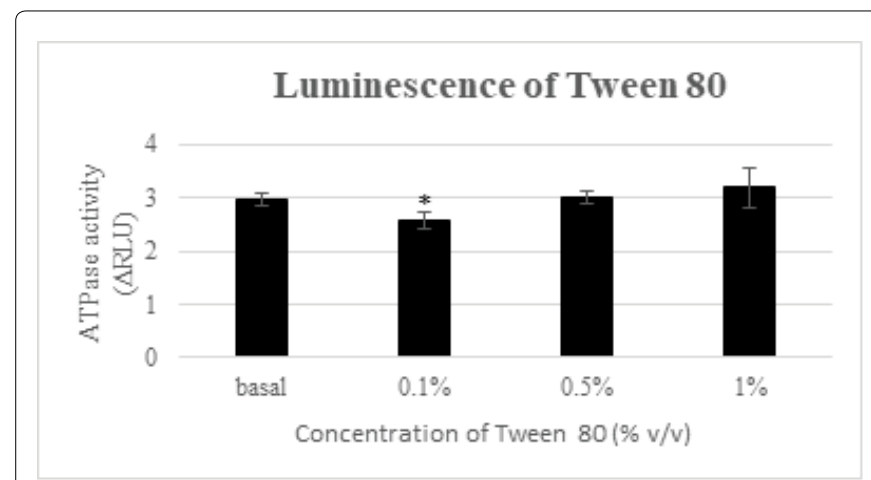

Figure 2: The influences of Tween 80 on P-gp activity. Results were expressed as means \pm S.D. $(n=3) .{ }^{*}$, $p<0.05$ compared with basal level of P-gp ATPase activity.

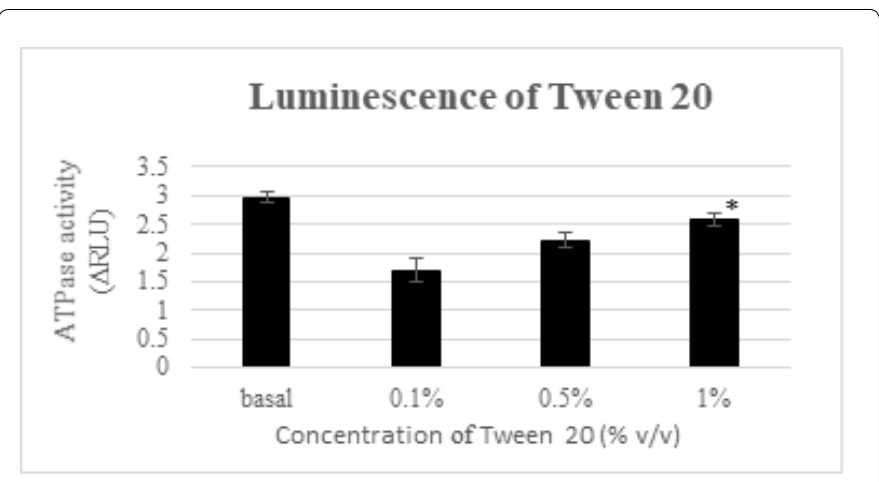

Figure 3: The influences of tween 20 on P-gp activity. Results were expressed as means \pm S.D. $(n=3)$. ${ }^{*}, p<0.05$ compared with basal level of P-gp ATPase activity.

\section{Conclusions}

The results presented in this study suggest that $0.1 \% \mathrm{v} / \mathrm{v}$ of Tween 80 , non-ionic surfactant, had an inhibitory effect on P-gp ATPase activity and while, $0.5 \% \mathrm{v} / \mathrm{v}$ and $1 \% \mathrm{v} / \mathrm{v}$ of Tween 80 possessed a stimulatory effect on P-gp ATPase activity. It was also demonstrated that three different concentrations of Tween 20 had an inhibitory effect on P-gp ATPase activity. A rational high-throughput screening of drug can be used for characterizing compounds as P-gp inhibitors/substrates/ stimulators because it provides a better approach to understand the enigma of P-gp in drug development and delivery.

\section{Acknowledgement}

The authors wish to thank the faculty of pharmacy, Mahidol University and Drug Discovery and Development center; Thammasat University to support the space for laboratory work.

\section{References}

1. Hellriegel ET, Bjornsson TD, Hauck WW (1996) Interpatient variability in bioavailability is related to the extent of absorption: implications for bioavailability and bioequivalence studies. Clin Pharmacol Ther 60: 601-607.

2. Hunter J, Hirst HB (1997) Intestinal secretion of drugs. The role of P-glycoprotein and related drug efflux systems in limiting oral drug absorption. Adv Drug Deliv Rev 25: 129-157.

3. Frank F, Wood KV (2006) Technology Review: Bioluminescent Assays for HighThroughput Screening. ASSAY and Drug Development Technologies 5: 127-136.

4. Higgins CF (1992) $A B C$ transporters: from microorganisms to man. Annu Rev Cell Biol 8: $67-113$. 